\title{
WAYS OF ADJUSTING sciendo THE TWO-STROKE DIESEL ENGINE TO BE RUN ON LIQUEFIED NATURAL GAS
}

DOI 10.2478/ntpe-2018-0039

\author{
dr inż. Mariusz Giernalczyk prof. AM \\ inż. Filip Łoński \\ Gdynia Maritime University, Poland \\ Wojciech Kaniak, MSc, P. Eng. \\ Rexroth Bosch Group, CANADA
}

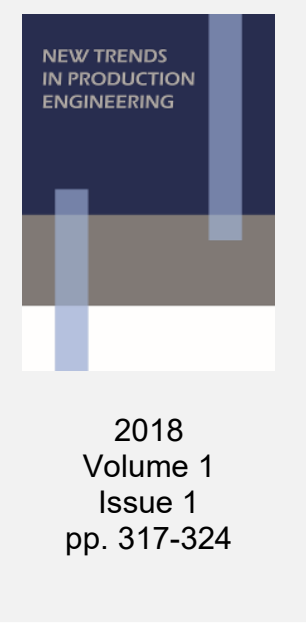

\begin{abstract}
This article attempts at assessing the feasibility and validity of adjusting the two-stroke diesel engine to be fuelled by liquefied natural gas (LNG). It discusses a set of modifications introduced onto one of the ships carrying liquefied natural gas. These changes consisted in adjusting the engines of the main drive so that they can be fuelled by gas. This has been achieved by the modification of the cylinder head and fuel supply installation. Parameter results of the modified engines obtained during sea trials have been presented. Both advantages and disadvantages resulting from gas combustion have been pointed out. Ultimately, the authors of this article assess the applicability of this solution to other LNG carriers.
\end{abstract}

Keywords: natural gas, dual-fuel diesel engines, LNG carriers

\section{INTRODUCTION}

Methane constitutes natural gas' main ingredient, which amounts to more than $90 \%$ of its composition. Besides methane, natural gas consists of some minor amounts of ethane, propane, butane and other organics and minerals. In order to simplify the process of transporting and storing, natural gas is converted to the liquid form (LNG). During that process, natural gas is cooled to the temperature of $-162^{\circ} \mathrm{C}\left(-260^{\circ} \mathrm{F}\right)$ as a result of which it can be stored in a volume 600 times smaller. What is more, the gas liquefaction involves removal of humidity, carbon dioxide, nitrogen and heavy nitro carbons. (Giernalczyk, 2007).

In order to transport liquefied natural gas (LNG) by sea, special ships called LNG carriers are used. The first sea gas transport took place in 1959. Despite the application of the most stateof-the-art insulating materials, there is still some evaporation of the LNG being transported. In an attempt to minimize losses resulting from this evaporation, some better and thicker insulating structures have been applied but it comes at the price of reduction of the cargo volume; this in turn means financial losses for the hauler. There is, on the other hand, also the possibility to re-liquefy gas in an appropriate installation and to re-direct again to the tanks. However, it is involved with a significant increase of energy expenditures and the need to recruit and hire the crew to support that process. What seems to be the most reasonable method is to use the vaporized gas as the power supply for the main drive engines (Giernalczyk, 2007; Zanne and Grcic, 2009). Economic reasons are here decisive. Unlike the liquid fuels, prices of the natural gas on the world markets are for long stable, and the cost [USD] of producing an energy unit [MWh] by an engine fuelled by gas is significantly lower than by the most popular heavy fuel IFO 380. It is presented in the Fig. 1.

The simplest way to use vaporized gas hereafter referred to as boil-off gas (BOG) is its combustion in a ship's boilers what produces steam which propels the turbines of the main drive. Such solutions were widely used in the older conventional LNG carriers. Still, the steam turbine is the least efficient main drive engine which is illustrated in the Fig. 2. 


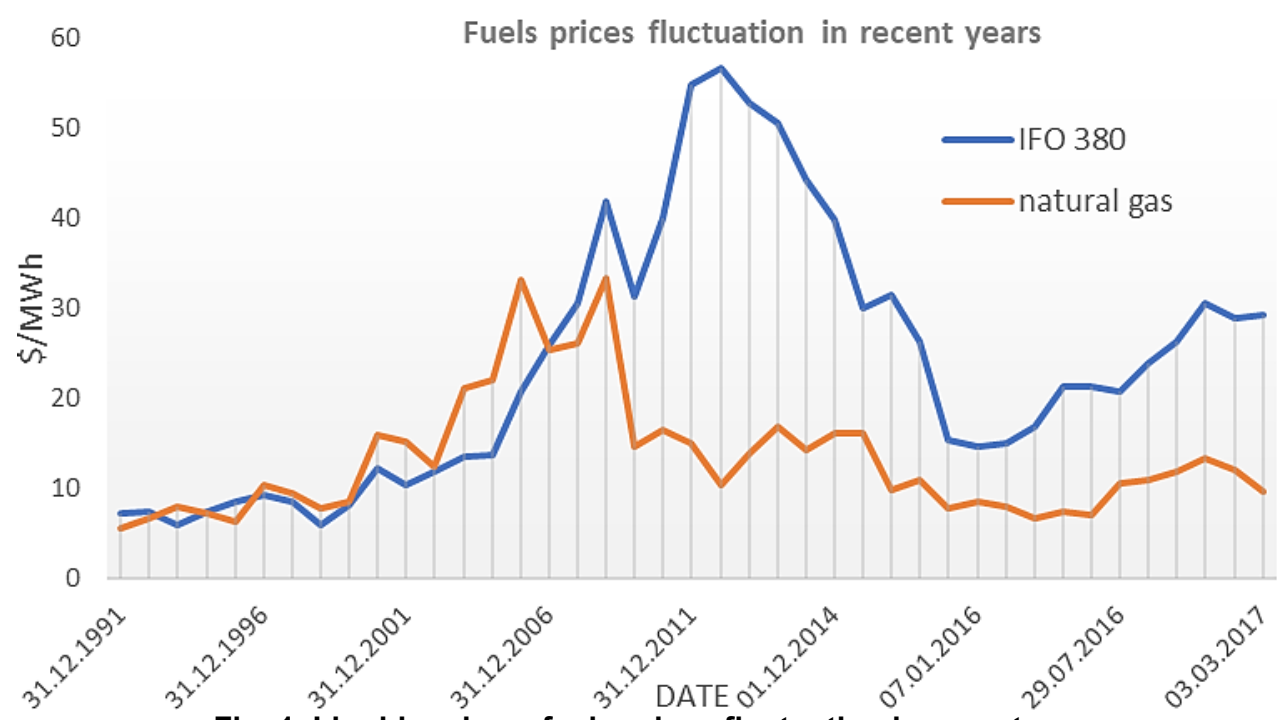

Source: DNV-GL, 2018

Fig. 1. Liquid and gas fuels prices fluctuation in recent years

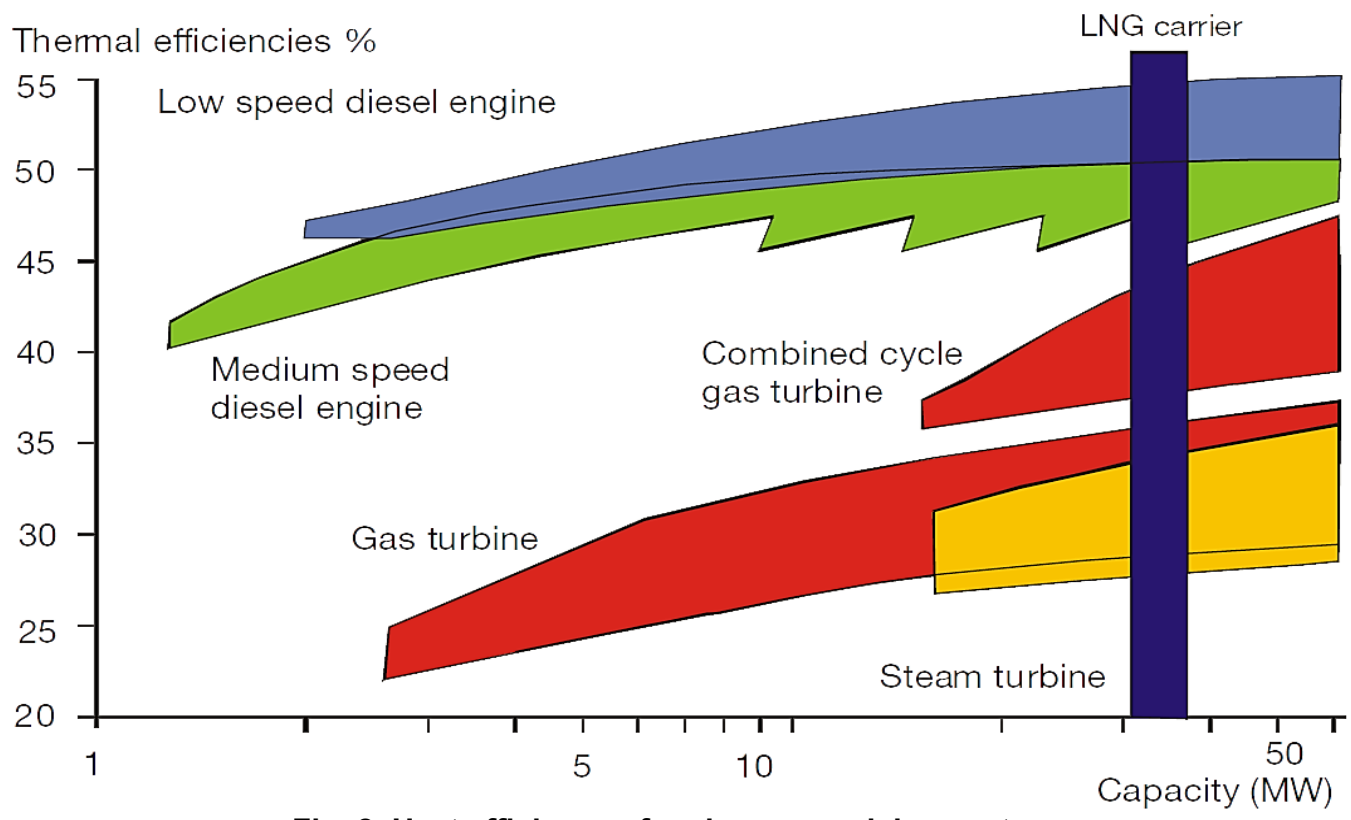

Source: MAN D\&T, 2003.

Thus, what seems to be a better way of using the BOG is its combustion in the diesel engines. Due to the fact that the amount of the BOG produced during a sea journey with cargo, let alone without it at all, might turn out to be insufficient to fully cover the engine's fuel needs, a concept of Dual-Fuel Engines comes to the rescue here (Giernalczyk, 2008).

The utilization of LNG as the source of power supply for ship engines not only brings measurable economic profits but also constitutes a method of reducing the emission of harmful substances to the atmosphere. It also enables adhering to very restrictive rules of environmental protection law, especially in the so-called special areas (Giernalczyk, 2008). The easiest way in which the Dual-Fuel Technology comes into use is in the form of medium-speed as well as high-speed Dual-Fuel four-stroke engines, both for the main drive as well as the generating sets, in which the vaporized gas is being supplied to the engine under low pressure $(0,5 \mathrm{MPa})$. Gas reaches intake air valves for each cylinder and mixes there with air in the combustion chamber. At present, there are many LNG Tankers in service which are powered by the four-stroke engines, which take advantage of the so-called Diesel Electric. (Giernalczyk, 2007). 


\section{ANALYSIS OF WAYS OF ADJUSTING TWO-STROKE DIESEL ENGINE TO BE RUN ON LNG ON AN EXAMPLE OF A SELECTED TANKER}

Undoubtedly, when it comes to the heat efficiency, pole position belongs to the combustion low-speed diesel engines (Fig. 2). However, the gas supply system which can be suited for a low-speed engine is way more complicated than for a medium-speed one. Among other things, it results from the fact that in order to compress gas, high pressure must be achieved (15-30 $\mathrm{MPa}$ ); for which some really energy-consuming multistage compressor units are required. $\mathrm{A}$ complex technical system, by its nature, is prone to movement disturbances and other malfunctions. That is a reason why the Dual-Fuel two-stroke Diesel engines for long had been remaining only in a design-experimental phase. In years $2011-2012$, almost $40 \%$ of newly-built LNG vessels were equipped with low-speed diesel engines (with re-liquefaction plant) or dual fuel diesel electric propulsion. Until today, none of LNG carrier is propelled by gas turbine (M Morsy El-Gohary, 2012).

In 2005, the MAN Company has won the contact with Qatargas consortium for equipping their big LNG carriers (Q-Max and Q-Flex class) with ME-series, electronically controlled, low-speed diesel engines. Initially, the application of Dual-Fuel engines with an option of running on the vaporized gas has been considered. However, due to the complexity of the gas supply system and lack of experience in exploiting such systems, the idea was abandoned. Ultimately, twinengine drives with engines running on liquid fuels have been chosen: 6S70ME-C and 7S70ME-C for Q-Flex and Q-Max classes respectively. The gas vaporized in them was being liquefied and re-directed back to the tanks.

In recent years, the world has witnessed a major breakthrough when first units propelled by the two-stroke, Dual Fuel diesel engines were put into service. Teekay LNG Partners ship-owner has a number of such ships in his fleet: Creole Spirit, Oak Spirit, Torben Spirit, each equipped with two engines: MAN D\&T type 5G70ME-GI (Significant Ships of 2013-2016, 2016).

Propelling two-stroke ship engines with natural gas has become possible not only in the case of LNG Carriers but for other types of units too. In 2015, the world's first containership fuelled by LNG called ISLA BELLA has been put into service for TOTE ship owner. What's responsible for supplying the main drive of this unit is the Dual-Fuel low-speed diesel engine - MAN D\&T 8L70ME-C8.2 Gl with the power of $21412 \mathrm{~kW}$ at the rotational speed of $98.5 \mathrm{rpm}$. When it comes to the engines responsible for powering the generating sets, these are three Dual-Fuel MAN D\&T engines 9L28/32DF with the power of $1845 \mathrm{~kW}$ each at the rotational speed of 720 rpm. LNG is currently an increasingly used solution for marine fuel. In August 2014, 50 vessels were already supplied with natural gas (excluding LNG carriers), (Significant Ships of 20132016, 2016; Byeong-Yong Yoo, 2017).

All this led Qatargas consortium to revisit the concept of Dual-Fuel engines as the main drive for the Q-Max and Q-Flex class vessels. A decision has been taken to adjust two engines of the main drive 7S70ME-C7, on one of the Q-Max class carriers being already in service, to be capable of combusting natural gas (7S70ME-GI version). It required some customization of the engine, so it combusts natural gas, and development of the gas supply system.

The customization of the engine consisted primarily in modifying the fuel supply system; particularly in piping both liquid and gas fuel to the cylinder head (Fig. 3).

The gas injection to the combustion chamber in itself is feasible thanks to the fact that the cylinder head is supplied with the gas injectors together with the ELGI valve (electronic gas injection) (Fig. 3). In order to ensure smooth engine operation on gas, it is essential to provide so-called liquid pilot fuel (i.e. small amount thereof just before the main injection), amounting to $5-8 \%$ of its volume. Research conducted by the manufacturer has proven that without such a pilot injection, the engine operates unstably; knocking combustion occurs or there might be even misfiring. The cause of this, among others, is the higher temperature of the vaporized gas' spontaneous combustion (Linwood et al., 2006). 


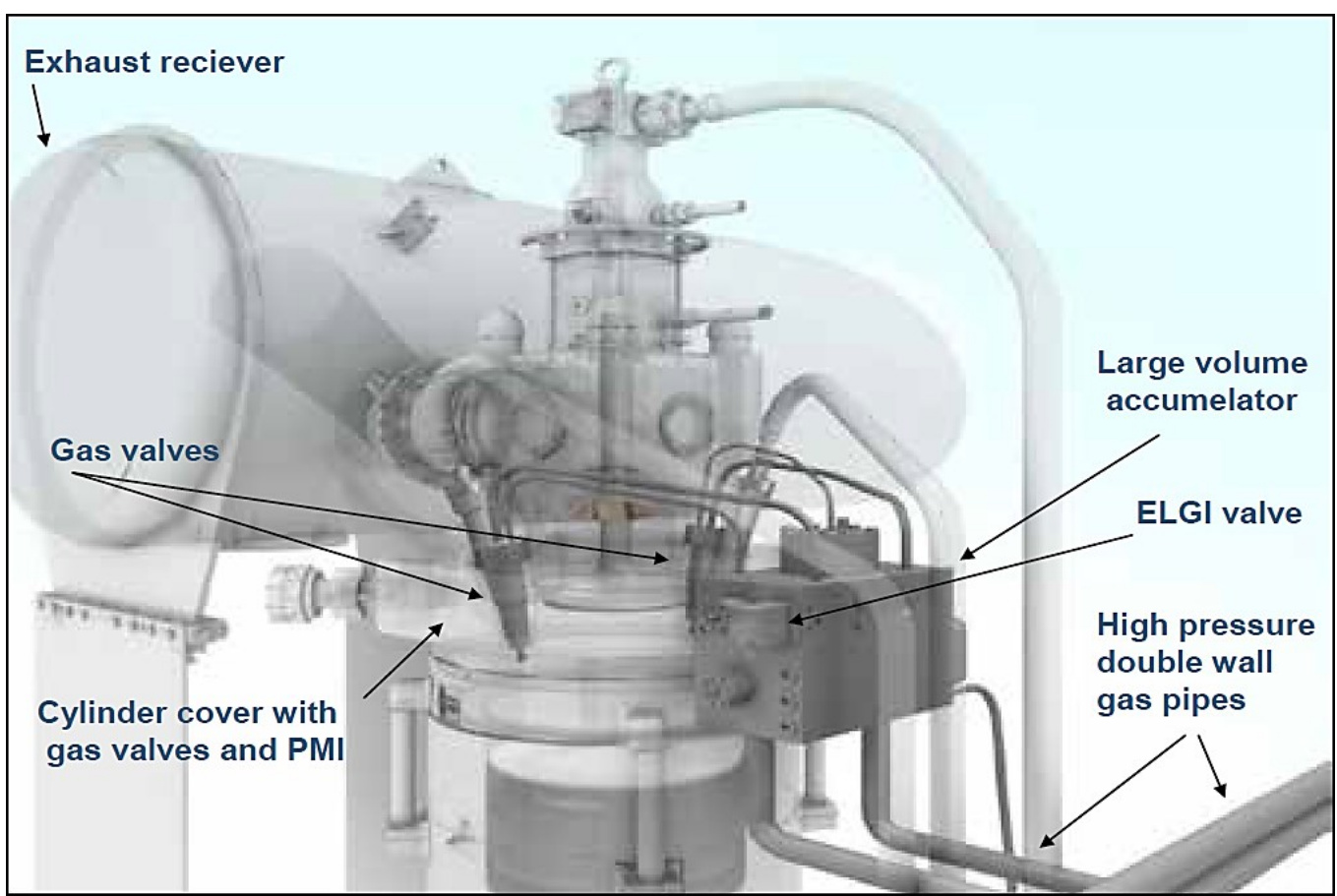

Fig. 3. ME-GI low-speed engine's modified fuel supply system

Source: MAN D\&T, 2014

ME-GI engines, apart from having all the systems widely used in all ME series engines, must be also additionally equipped with a number of other installations, like, among others (MAN D\&T, 2005):

- Ventilation system of the spaces between the interior and exterior compartments of the double-walled installation fuelling the engine with the vaporized LNG gas.

- Sealing oil system, the aim of which is to separate the main gas injection from the pilot fuel dose.

- PLC control unit - comprising of a set of sensors and analyzers. Its main function is to turn on and off the gas supply installation. In case of a breakdown, the PLC control unit will automatically switch from gas to the heavy fuel supply without any losses of power in the main engine.

- IGS system (i.e. Inert Gas System) - part of the PLC control unit; its purpose is to keep the main engine supply installation free from gas.

Low-speed Dual-Fuel ME-GI engines can work in any configuration fuelled by the vaporized gas and/or liquid fuel, but most often they operate in the following modes:

1. Fuel-oil-only mode - this mode is chosen when:

- A ship is underway without cargo and the LNG residues are not enough to fuel the engine

- The pressure of the fuelling gas is too low

- A malfunction prevents from using boil-off gas as fuel

- During port maneuvers (to ensure higher safety)

2. Minimum-fuel mode - normally used if:

- A ship is underway and the amount of vaporized LNG gas is enough to satisfy $100 \%$ of the main engine's load

3. Specified gas mode - this mode is set manually by the operator (mechanic) from the operational panel:

- An operator may individually adjust the amount of both gas and fuel to the current operating conditions

In order to achieve the engine's thermal efficiency of $50 \%$ it must be ensured that the gas flowing to the engine is under the pressure between 15 and $30 \mathrm{MPa}$. With engine's nominal load, pressure of the gas reaches up to $30 \mathrm{MPa}$, while with lower loads, the gas pressure 
decreases linearly to reach $15 \mathrm{MPa}$ with $30 \%$ of the load. Engine's gas supply system requires then application of dedicated compressor units. That is why the modernized ship has been equipped with special high-pressure pumps. An engine's high-pressure gas supply system used on that unit can be seen in Fig. 4.

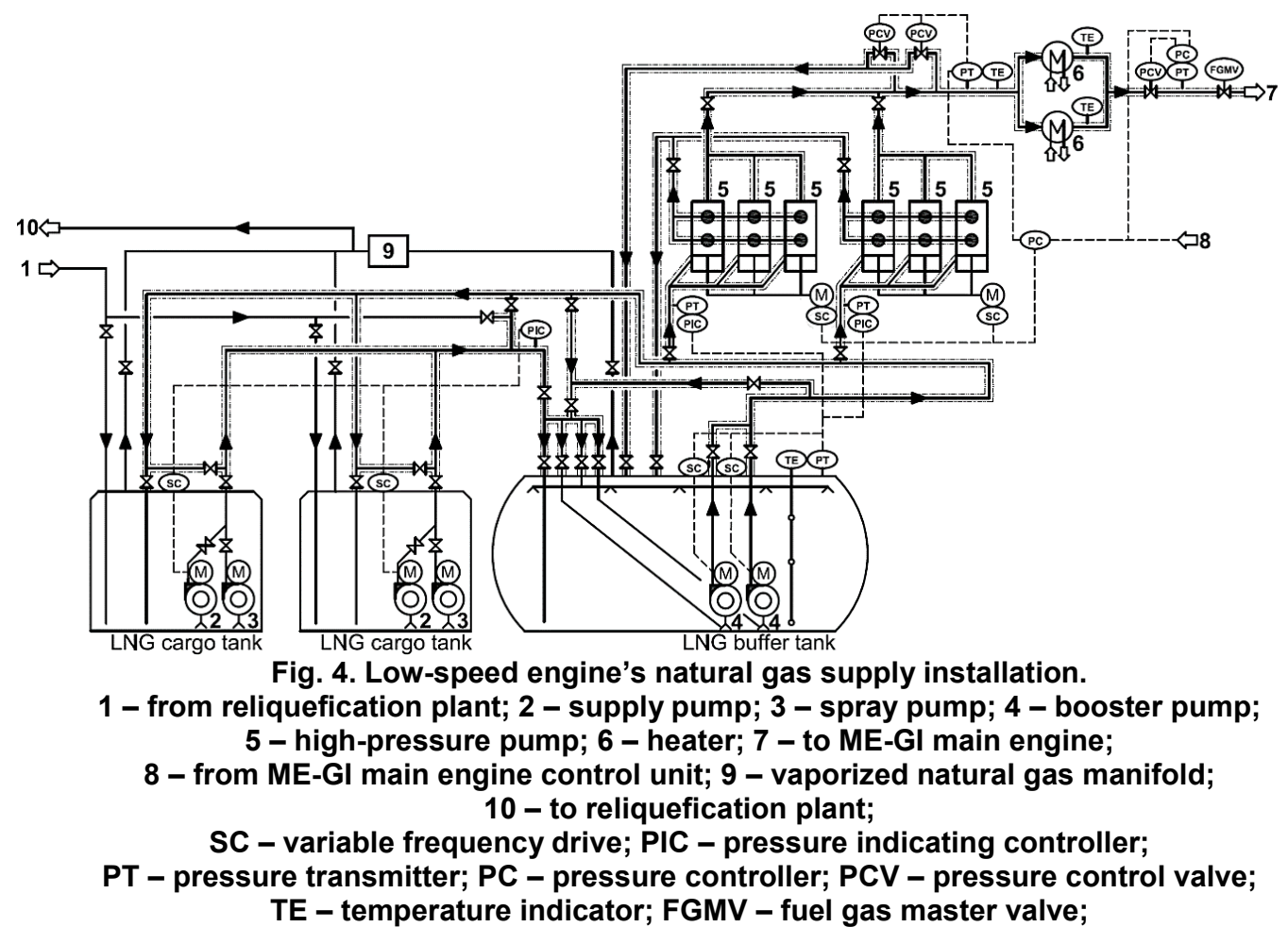

In order to supply the engine with well-prepared gas fuel, it is essential that a series of modifications are made. In the cargo tanks, additional supply pumps are installed 2 . These pumps are then connected to the existing pipeline for pumping gas for cooling down the tanks. It enables the transportation of the liquefied gas to the buffer tank by means of supply pumps 2 as well as spray pumps 3 . Booster pumps, placed directly within the buffer tank, are pumping LNG to the suction pipeline of the high-pressure pumps 5 . Gas pressure at its pressing is regulated by the means of adjusting the rotation speed of the pump. Then, gas, compressed to the required pressure, goes to the heater 6 , where the right temperature is provided by the heating medium - the water-glycol mixture. It enables vaporization and heating the gas up to the temperature of 45 degrees C. Finally, the gas goes to the very engine where it is combusted.

Before introducing the modifications, the vaporized gas would be normally directed via the pipeline 10 for re-liquefaction. Once the installation of the engine fuel supply got expanded, an opportunity has arisen that the gas can be taken directly from the liquefying installation by the pipeline 1 and directed to the buffer tank.

High standards demanded from the LNG delivery installations made it obligatory to use doublewalled pipelines. The safety system constantly collects and samples the air from between the walls inside the pipeline. In case of detection of gas particles in there, the engine's gas supply system is immediately switched off and the quick-closing valves - cut off. The automation enables a smooth transition from gas to liquid fuel without any stoppages in the engine's operation.

Once the adjusting works were completed and attempts to run the engines on gas made, some operating issues started to appear, especially at the beginning; among other things, injector sprayers got, quite often, melted. After consultation in this regard with the engines manufacturer, new sprayers were manufactured, this time made of tin-coated steel and this solved the problem straightaway. 
The adjustment of the engines of the main drive, so that they can run on the vaporized gas, had as one of its aims lowering the costs of operating a ship. In recent years, the cost of producing an energy unit from an engine running on liquid fuel has exceeded threefold the cost of producing the same amount of energy from an engine operating on natural gas (Dwg 1).

After completing the modernization of the Q-max class vessel so as to adjust it to operate on gas fuel as its main drive, the ship's fuel consumption has been measured with various engine loads and the minimal amount of pilot heavy fuel, amounting to ca. $5 \%$ of the volume. The findings of this measurement can be found in Table 1.

Table 1

Main engines' consumption for gas fuel and pilot dose of liquid fuel during sea trials.

\begin{tabular}{|c|c|c|}
\hline Engine load [\%] & Pilot oil consumption [t/24h] & Natural gas consumption [t/24h] \\
\hline 60 & 14,16 & 69,31 \\
\hline 75 & 15,40 & 84,10 \\
\hline 85 & 17,86 & 100,18 \\
\hline 90 & 16,66 & 108,48 \\
\hline 100 & 15,46 & 117,14 \\
\hline
\end{tabular}

Source: MAN D\&T, 2015

For the purpose of analysis and calculation of the costs of running the main drive on fuel, an assumption has been made that the ordinary conditions of operating a vessel are with the main engines' load at the level of $85 \%$. The parameters of the operation of an engine with such a load can be found in Table 2 and its gas consumption (both engines) - in Fig. 5.
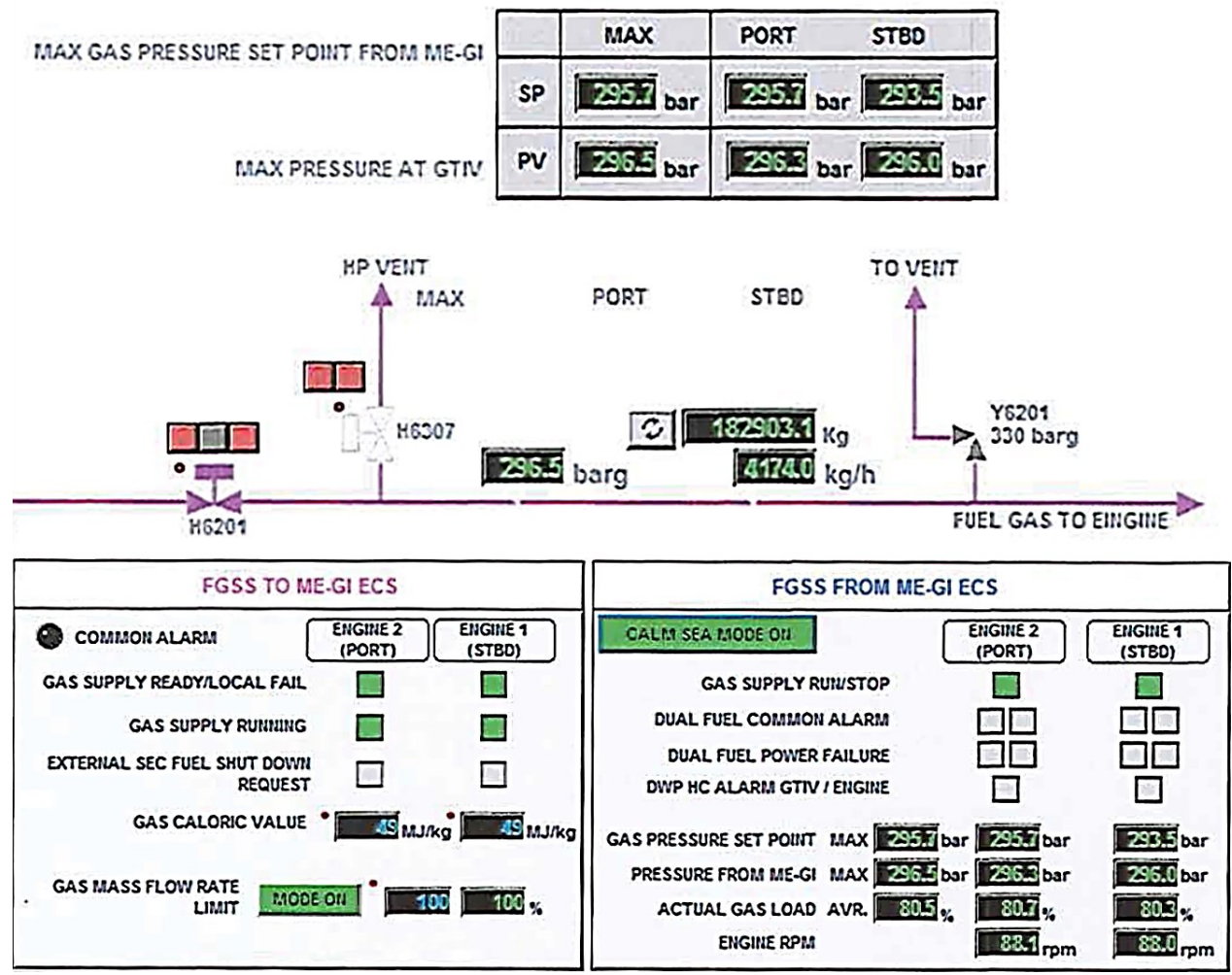

Fig. 5. Engine control room's recording of the main engines gas consumption Source: MAN D\&T, 2015. with the $85 \%$ load

While run on natural gas, load amounting to $85 \%$ for both engines of the main drive and the pilot dose of heavy fuel on a minimal level (ca. $5 \%$ ), the heavy fuel consumption for both engines amounted to 17.86 tons and for natural gas -100.18 tons. Based on the fuel prices from recent years, shown in the Fig. 1, costs of running the vessel's engines for 24 hours can be estimated to be around $\$ 27,153$ USD. 
When running the engines with the $85 \%$ load only on the liquid fuel, two $7 \mathrm{~S} 70 \mathrm{ME}$ engines consume approximately 140 tons of heavy fuel daily what generates cost of $\$ 44,800$ USD (Table 2).

It can be then concluded from this comparative analysis that the cost of operating a unit fuelled by gas and the minimal required dose of heavy fuel is almost two times lower than when fuelling it by heavy liquid fuel only.

Table 2

Performance of the 7S70ME-C7-GI main drive engine with the $84.1 \%$ load.

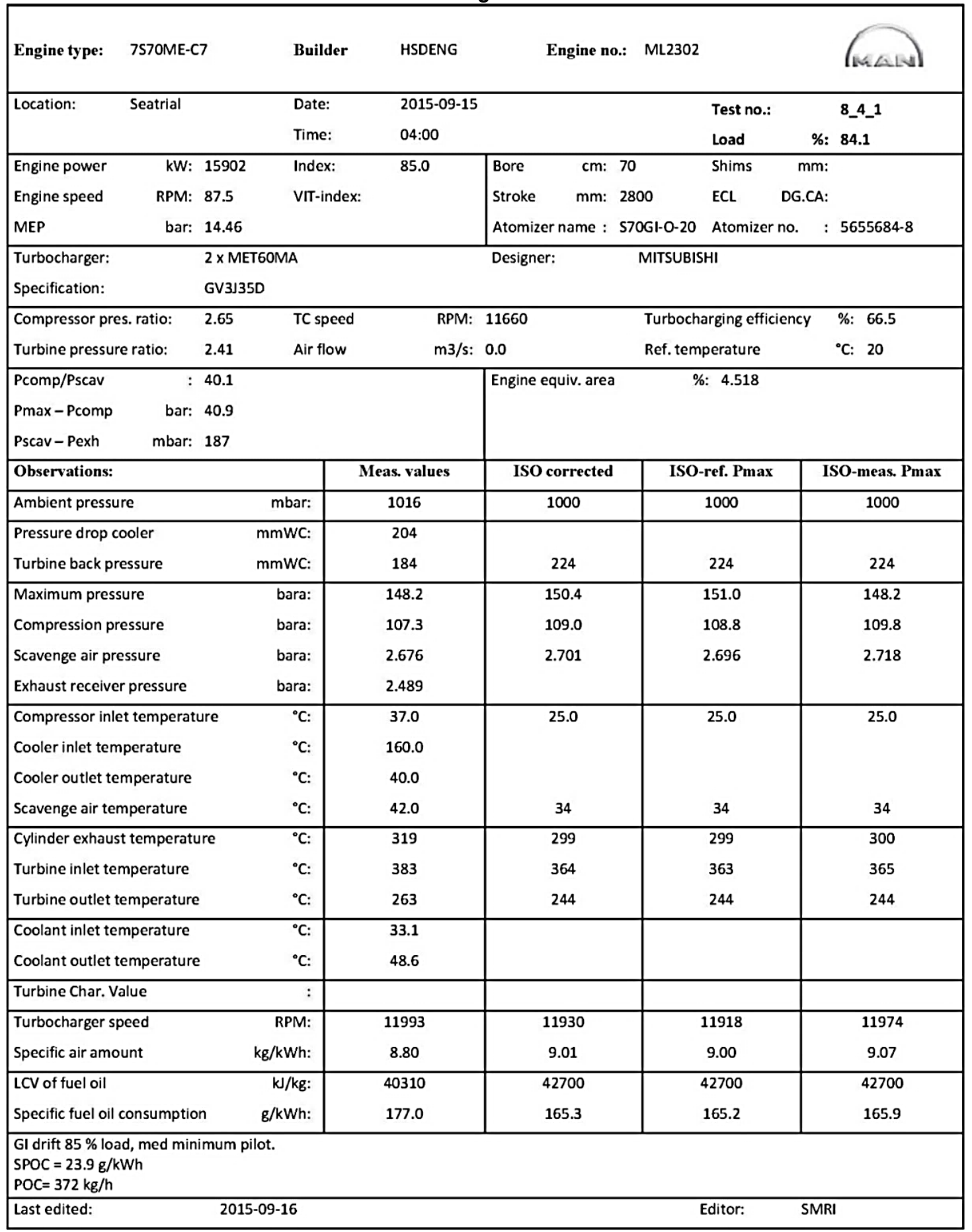

Source: MAN D\&T, 2015

\section{CONCLUSION}

It is much probable that in the upcoming years, the choice of propulsion system for new built big LNG carriers will be oriented towards Dual-Fuel two-stroke engines, aside from the already 
commonly used Dual-Fuel four-stroke engines. What decides about such an approach is their top performance when compared to other heat engines and the fact that the price of gas is stable and significantly lower than the ever-changing price of liquid fuels. Additionally, the environmental protection law, more restrictive with every day, may have huge impact on it too - it comes in play especially in the so-called ECA's (Emission Control Areas), having as its aim to reduce the emission of harmful substances to the atmosphere. Combustion of the natural gas in engines ensures meeting all the standards and rules, even the most restrictive ones. The main decisive factors which dictate such a choice are the economic indicators and the environmental protection law. Still, at the end of the day, it is the reliability of these devices and the experience of using them that will verify.

Presently, the costs of building a ship equipped with a Dual-Fuel engine are way higher than constructing a vessel equipped with a conventional unit. Possibly, what could contribute to lowering such costs is a replacement of Dual-Fuel engines with compression ignition with the engines with spark-ignition, which can be run on gas solely, without the need of adding the pilot dose of liquid fuel. A ship's fuel system could be then much simplified and would practically consist of tanks and gas installations only.

\section{REFERENCES}

Byeong-Yong Yoo. (2017). Economic assessment of liquefied natural gas (LNG) as a marine fuel for CO2 carriers compared to marine gas oil (MGO). Elsevier, Energy. Vol. 121, pp. $772-780$.

DNV-GL. (2018) Current price development oil and gas [online]. Available at: www.dnvgl.com/maritime/lng/current-price-development-oil-and-gas.html [Accessed 05 Sep. 2017].

Giernalczyk M. (2007) Analysis possibilities of cost reduction related to boil-off fuel gas being carried on LNG Gas Carriers. Journal of KONES, Vol. 14, No. 2, pp. 153-160.

Giernalczyk M. (2008) Analysis possibilities of the application of dual fuel engines as a main propulsion on LNG Gas Carriers. Journal of KONES, Vol. 15, No. 4, pp. 147-155.

Linwood J., Jong-Pil Ha, Kjeld Aabo, Rene S Laursen. (2006) LNG Gas Carrier with High Pressure Gas Engine Propulsion Application. [ebook] Dubai: GasTech. Available at: http://www.witherbyseamanship.com/Ing-gas-carrier-with-high-pressure-gas-enginepropulsion-application-downloadable-product.html [Accessed 10 Sep. 2017].

MAN Diesel \& Turbo. (2003) LNG Carrier Propulsion by ME-GI Engines and/or Reliquefication [pdf]. Denmark.

MAN Diesel \& Turbo. (2014) LNG Carriers with ME-GI Engine and High-Pressure Gas Supply System [pdf]. Denmark.

MAN Diesel \& Turbo. (2005) S70ME-GI Project Guide. 2nd Edition [pdf]. Denmark.

MAN Diesel \& Turbo. (2015) Sea trials results of 7S70ME-C7-GI.

Morsy El-Gohary M. (2012). The future of natural gas as a fuel in marine gas turbine for LNG carriers. Proceedings of the Institution of Mechanical Engineers, Part M: Journal of Engineering for the Maritime Environment, vol. 226, 4: pp. 371-377.

Significant Ships of 2013-2016. (2016) A publication of the Royal Institution of Naval Architects. London UK.

Zanne M., Grcic M. (2009) Challenges of LNG (liquefied natural gas) carriers in 21(st) century. Promet - Traffic \& Transportation. Vol. 21, No. 1, pp. 49-60. 